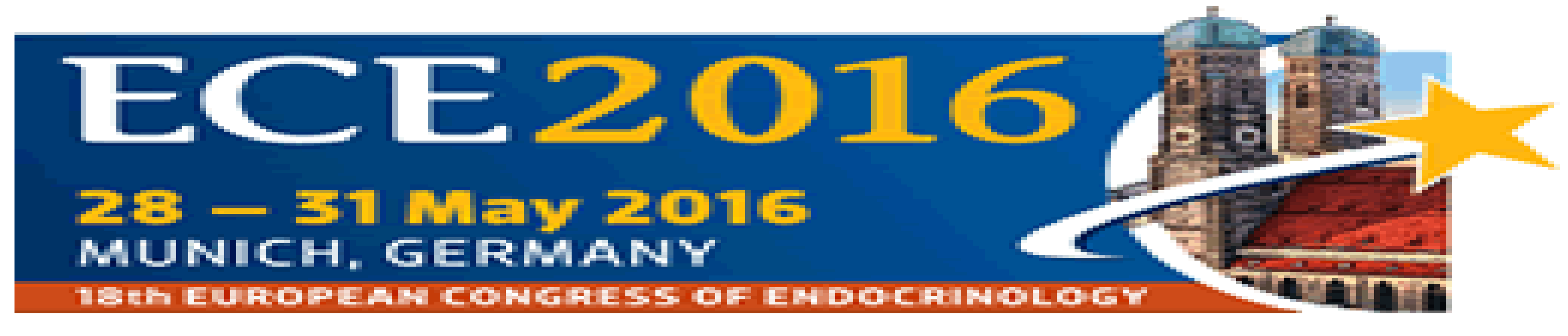

\title{
AN UNCOMMON REASON OF OSTEOPOROSIS: SPONDYLOEPIPHYSEAL DYSPLASIA CONGENITA (SEDC)
}

\author{
Onur ELBASAN ${ }^{1}$ PInar SISMAN², Soner CANDER², Ozen OZ GUL ${ }^{2}$, Erdinc ERTURK², \\ Canan ERSOY ${ }^{2}$ \\ Uludag University, Faculty of Medicine, Department of Internal Medicine, Bursa, Turkey ${ }^{1}$, \\ Uludag University, Faculty of Medicine, Department of Endocrinology and Metabolism, Bursa, Turkey ${ }^{2}$
}

INTRODUCTION: SEDC is a rare congenital disease of skeletal system, which is characterized by short stature, shortage of trunk and mostly affect vertebral column and epiphysis of long bones $(1,2)$. In this case report, we aimed to represent a patient complaining of short stature and referred to our hospital, who was detected to have an early onset osteoporosis accompanied by proximal femoral aplasia; in the light of literature.

CASE: A 21 years old female, referred to our hospital since she was complaining of short stature. In the past, when she was 13, she was also admitted to a pediatric endocrinology department for the first time and for the same reason. According to this firs assessment, her height was $125,7 \mathrm{~cm}$, weight $35,7 \mathrm{~kg}$ and had a pelvic deformity. By performing a skeletal scanning in that period; a platispondilia like appearance in the vertebral column, an increase in lumber lordosis, disappearance of both femoral heads, shortening of femoral neck, lateral subluxation of proximal femur were detected and bilateral femoral osteotomy and a fixation were performed respectively. When we focused on the patient's history, we learned that when she was 3 months, she had to use a corset because of a congenital hip dislocation. In the physical examination we noticed coxa vara, scoliosis and has a flattened face. The biomedical parameters are all summarized in Table 1. In the skeletal examination we noticed deformation and stabilization materials in the femur heads (Figure 1) and counter rotation developed in cervical axis which wasn't exist previously, mild loss of intervertebral disc height in C3, C4, C5, C6 (Figure 2).

We calculated lumbal total $Z$ score as -3.2 . It was thought that the reason of premenopausal osteoporosis was SEDC. We prescript teriparatide because of her age and high grade of osteoporosis.

Table 1.

\begin{tabular}{|l|l|l|}
\hline Laboratory tests & $\begin{array}{l}\text { Laboratory } \\
\text { findings }\end{array}$ & Normal Range \\
\hline $25-\mathrm{OH}$ Vitamin D & $10.4 \mu \mathrm{g} / \mathrm{l}$ & $10-60$ \\
\hline Parathormone & $77.1 \mathrm{pg} / \mathrm{mL}$ & $15.0-68.3$ \\
\hline Thyroid Stimulating Hormone & $3,02 \mu \mathrm{IU} / \mathrm{mL}$ & $0.350-4.940$ \\
\hline Thyroxine & $1,04 \mathrm{ng} / \mathrm{dL}$ & $0.7-1.48$ \\
\hline Follicle Stimülating Hormone & $2.44 \mathrm{mlU} / \mathrm{mL}$ & $1.80-11.78$ \\
\hline Luteinizing Hormone & $4.4 \mathrm{mlU} / \mathrm{mL}$ & $1.80-11.78$ \\
\hline Prolactin & $29.50 \mathrm{ng} / \mathrm{mL}$ & $1.20-29.93$ \\
\hline Growth Hormone & $8.67 \mathrm{ng} / \mathrm{mL}$ & $0.06-5.00$ \\
\hline Somatomedin C & $208 \mathrm{ng} / \mathrm{mL}$ & $116.0-358.0$ \\
\hline
\end{tabular}

DISCUSSION: Although osteoporosis was reported in Spondiloepiphyseal dysplasia tarda cases, we didn't notice any report mentioning about the relationship between SEDC and osteoporosis; in the literature. As a conclusion, skeletal dysplasia which is mostly presented with short stature, should always be in mind as one of the prediagnosis in any case of early onset osteopenia and osteoporosis.

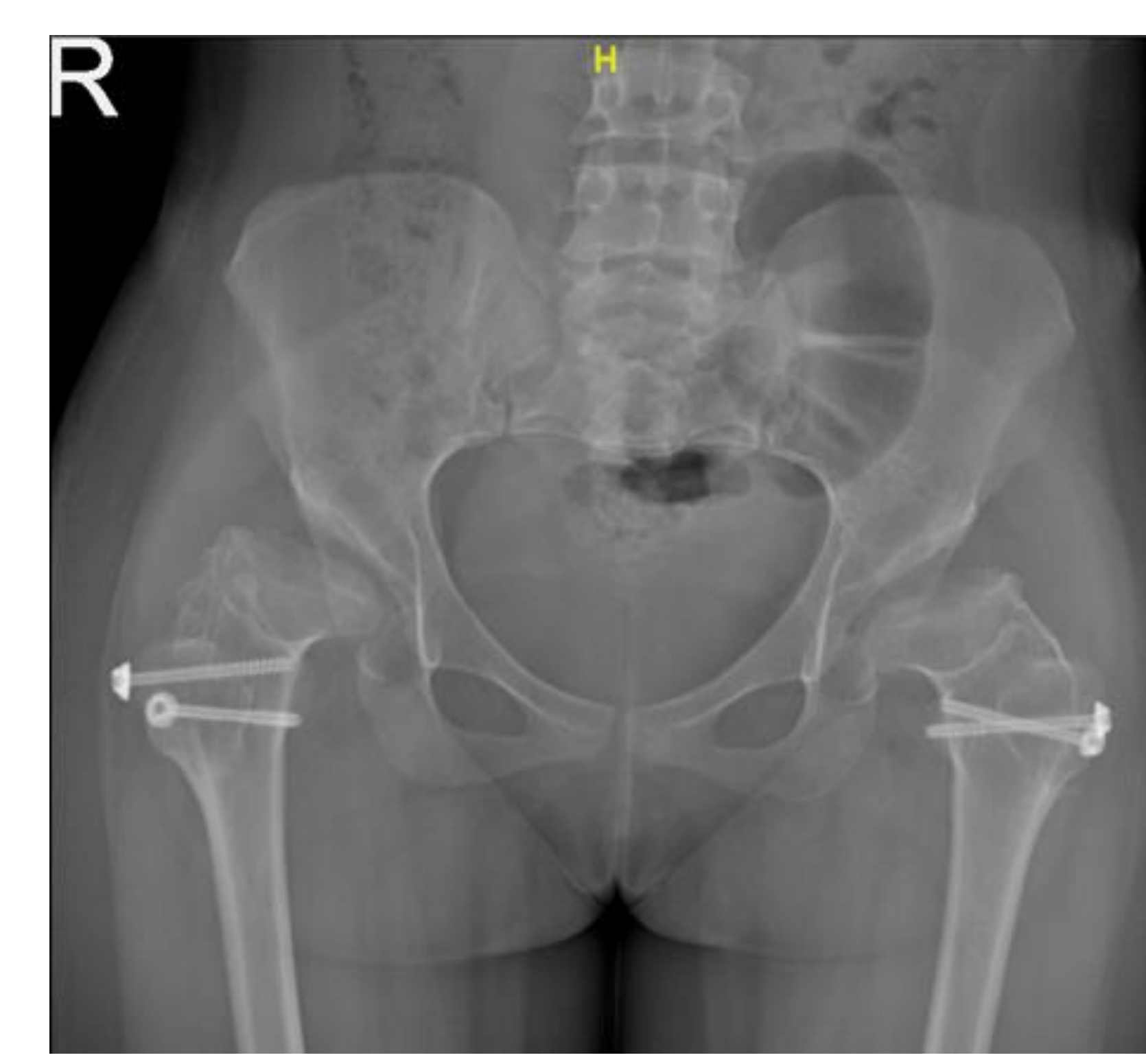

Figüre 1

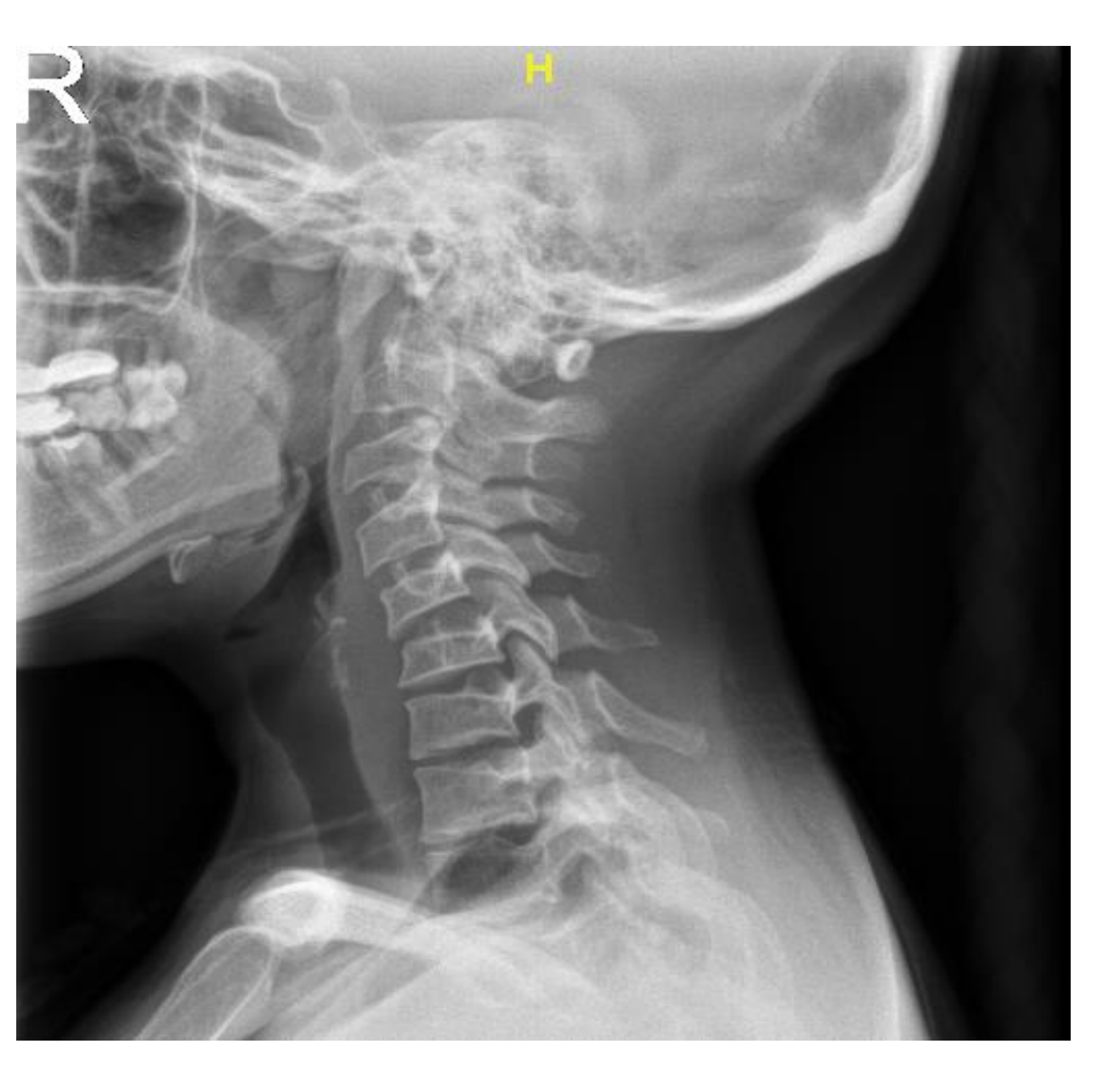

Figure 2 